\title{
Mathematics Anxiety and Its Development in the Course of Formal Schooling-A Review
}

\author{
Chiara Eden ${ }^{1}$, Angela Heine ${ }^{1}$, Arthur M. Jacobs ${ }^{1,2}$ \\ ${ }^{1}$ Department of Psychology, Freie Universität Berlin, Berlin, Germany \\ ${ }^{2}$ Dahlem Institute for Neuroimaging of Emotion (D.I.N.E.), Berlin, Germany \\ Email: Chiara.Eden@zedat.fu-berlin.de \\ Received April 13 $3^{\text {th }}, 2013$; revised May $16^{\text {th }}, 2013$; accepted June $14^{\text {th }}, 2013$
}

\begin{abstract}
Copyright (C) 2013 Chiara Eden et al. This is an open access article distributed under the Creative Commons Attribution License, which permits unrestricted use, distribution, and reproduction in any medium, provided the original work is properly cited.
\end{abstract}

\begin{abstract}
The purpose of the this article is to provide an overview of the current state of research concerning the development, determining factors and effects of mathematics anxiety, particularly with regard to young elementary school age level populations. Assessment instruments, potential risk-factors, consequences of mathematics anxiety, as well as approaches to intervention are summarized. Owing to the small number of studies focusing on mathematics anxiety in young children, findings from adult studies are briefly recapitulated. The available data emphasizes the need for systematic research that focuses on the one hand on the onset of mathematics anxiety at a young age, and on the other follows the development of longer periods of time. Furthermore, multi-method research designs may be the means to gain deeper insight into the dynamics of causes and effects when the interaction of mathematics anxiety and mathematical abilities are under scrutiny. Only by implementing longitudinal studies that involve different types of data and the formulation of complex models of the dynamics of mathematics anxiety over time, can its determining factors and its effects be generated.
\end{abstract}

Keywords: Mathematics Anxiety; Assessment; Mathematical Performance; Working Memory; Gender; Stereotype; Self-Efficacy; Development; Interventions

\section{Introduction}

According to statistical estimations, roughly $20 \%$ of the population suffer from more or less severe psychological or physiological symptoms related to feelings of anxiety when confronted with tasks that require the manipulation of numerical information (i.e. one out of five persons belongs to the group of high-math-anxious individuals; Ashcraft \& Kirk, 2001). This, along with the typically ensuing withdrawal from mathematics-associated situations, implicates far-ranging difficulties for educational contexts as well as everyday life for the affected individuals.

It is common knowledge that some students experience mathematics as especially challenging and even aversive, independently from their general level of competencies (Ashcraft, Krause, \& Hopko, 2007; Hembree, 1990). Unfortunately, a student's aversive reactions to mathematics are often reinforced by their implicitly or even explicitly approving social contexts (e.g. Beilock, Gunderson, Ramirez, \& Levine, 2010). Consequently, the systematic avoidance of mathematics-related situations and, in later stages of development, of mathematics-associated careers (e.g. Ashcraft \& Faust, 1994; Hembree, 1990), are rather the rule than the exception. Considering the potentially farreaching effects not only for the individual, but also for the society, and additionally, taking into account the high prevalence rates, it is surprising that adequately complex models of the development of mathematics anxiety are still widely lacking even after decades of research into mathematics anxiety.
Initially described as mathemaphobia by a teacher who referred to her students' striking emotional reactions in the face of mathematical tasks and challenges (Gough, 1954), this phenomenon has gained increasing attention not only from the educational practice, but also from the scientific community. In the 1970 s, a widely accepted definition of the phenomenon was provided, describing mathematics anxiety as "[...] a feeling of tension and anxiety that interferes with the manipulation of numbers and the solving of the mathematical problems in a wide variety of ordinary life and academic situations" (Richardson \& Suinn, 1972: p. 551). The detrimental consequences for the individual and his or her development were not yet considered in this description. Recent scientific approaches investigated these aspects in more detail. However, the better part of the available empirical studies focus on individuals at the end of their formal education. This is unfortunate, as most of the detrimental impact of mathematics anxiety has taken its toll by that time, which interferes with the aim to gain a deeper understanding of biasing factors.

However, despite the lack of studies focusing on the early years of formal schooling (i.e., early elementary school age), considerable insight has been gained, specifically in the context of studies involving older students. With the present review article, an overview of the current research on mathematics anxiety, its assessment, the empirical findings on mathematics anxiety at an early age, remedial intervention, as well as relevant open issues will be provided. 


\section{Differentiation from Related Constructs}

As early as the first mention of mathematics anxiety, its discrimination from similar constructs has been considered. Dreger and Aiken (1957) made three assumptions about mathematics anxiety and its associations with related constructs. First, they suggested mathematics anxiety to be a unique construct, despite a definite relationship with general anxiety. Second, they assumed mathematics anxiety as not entirely explained by general ability, i.e. intelligence. Third, they suggested a negative relationship between academic performance and mathematics anxiety. Since then, all three predictions were confirmed by research on mathematics anxiety (see Hembree, 1990; Ma, 1999). Correlations between mathematics anxiety and general anxiety are reported to be .35 , between mathematics anxiety and IQ -.17, and, finally, between mathematics anxiety and mathematical achievement -.27 (pre-college level: Ma, 1999) to -.31 (college level: Hembree, 1990). These findings do not generalize to younger populations (i.e. elementary school level) as studies on children are still wanting.

The most extensive overlap between mathematics anxiety and potentially related constructs, however, was not mentioned by Dreger and Aiken's early work (1957), that is, the interrelation between mathematics anxiety and test anxiety (.52; Hembree, 1990). But since this relationship is considerable, mathematics anxiety's status as a unitary construct was investigated in more detail. In this vein, Dew and colleagues (1984), for instance, found that different assessment scores of mathematics anxiety are intercorrelated more strongly than they are correlated with test anxiety scores. Due to such empirical results, Hembree (1990) assumes the two constructs to be distinct, just as Ashcraft and Ridley (2005) conclude that in adults, about two thirds of mathematics anxiety's variance cannot be explained by test anxiety. Nevertheless, this refers to adult data only.

\section{Origins of Mathematics Anxiety}

So far, research has focused mainly on the consequences of mathematics anxiety. Its antecedents, however, remain largely unexplored. That is, only a small number of studies have focused on mathematics anxiety as a dependent variable (Jain \& Dowson, 2009). However, while little is known about how mathematics anxiety actually develops, it is generally assumed to be multifactorial in its origins.

Jain and colleagues (2009) described mathematics anxiety as a consequence of "an inability to handle frustration, excessive school absences, poor self-concept, internalized negative parental and teacher attitudes toward mathematics, and an emphasis on learning mathematics through drill without "real" understanding" (p. 240). A more concise description of the causal factors is provided by Devine and colleagues (2012) who classified variables systematically related to the development of mathematics anxiety into three groups, namely, environmental variables, intellectual variables and personality variables. Environmental variables include negative experiences in class or in family contexts, teacher and parent characteristics, as well as extrinsic expectations. Intellectual variables include the child's level of more general cognitive abilities, while personality variables comprise concepts such as self-esteem, self-concept, attitude, confidence and learning behavior.

In the following, relevant variables will be outlined in more detail following the categorization provided by Devine and colleagues (2012), even though classifying a certain variable as belonging to one category or the other is not always unequivocal.

\section{Environmental Influences}

Critical for the development of mathematics anxiety are the attitudes, stereotypes and the teaching style of a child's teachers, since they affect a student's attitudes, motivations, and learning activities in a very direct manner (Ashcraft \& Ridley, 2005). Research has shown that distant and unsupportive attitudes on the part of the teacher lead to avoidance on the part of the students (Turner et al., 2002). Ashcraft and Ridley (2005) assume that a teacher's negative attitude and classroom style in combination with being unsupportive in general, create avoidance reactions and feelings of anxiety related to mathematics and to mathematics testing in students.

Moreover, it was found that female elementary school teachers, who are themselves anxious about mathematics, pass their negative attitude down to their students. Interestingly, girls seem to be more affected by female teachers' attitudes as they are found to endorse inappropriate stereotypes more readily than boys (i.e. "boys are good at math, girls are good at reading"; Beilock et al., 2010). Similar associations between levels of mathematics anxiety and students' previous experiences in the context of formal mathematics education were reported by Harper and Daane, (1998), and Jackson and Leffingwell (1999).

However, not only teachers' but also parents' attitudes influence a child's attitude towards mathematics. It has been shown, for instance, that a parent's belief about their child's mathematical abilities are systematically related to a student's mathematical self-efficacy beliefs and performance scores (Eccles, Jacobs, \& Harold, 1990). Furthermore, Eccles and colleagues (1990) state, that "if parents hold gender-differentiated perceptions of, and expectations for, their children's competencies in various areas, then, through self-fulfilling prophecies, parents could play a critical role in socializing gender differences in children's self-perceptions, interests, and skill acquisition" (p. 189). Since gender and gender stereotypes are relevant issues in the context of research on mathematics anxiety, these factors will be discussed separately.

\section{Cognitive Variables}

It is tempting to assume mathematics anxiety to be directly related to poor mathematical competencies which, in turn, are determining experiences of threat in classroom situations. Challenging such a seemingly straightforward explanation, Suinn and Edwards (1982) point out that about half of the variance in mathematics performance measures can be explained by other than intellectual factors. Nevertheless, intellectual aspects (e.g. good abstract thinking abilities) can be assumed to diminish the risk for developing mathematics anxiety.

Another domain-general factor contributing to the development of mathematics anxiety may be poor visuo-spatial processing abilities. Maloney and colleagues (Maloney, Waechter, Risko, \& Fugelsang, 2012), for instance, suggest that higher mathematics anxiety in females may in part be mediated by sex differences in visuo-spatial processing abilities. That is, poor visuo-spatial processing abilities may affect the development of mathematics anxiety, mediated by poor mathematical abilities. 
However, the available empirical data concerning a casual link between poor visuo-spatial skills and mathematical abilities are inconclusive (but cf. Rotzer et al., 2009). Ben-Zeev and colleagues (2005), for example, suggest that differences in visuospatial abilities may actually be largely attributable to environmental influences and hence, suggest gender-related differences rather than sex-related differences to play a major role in this context.

\section{Personality Variables}

According to Stuart (2000), the development of mathematics anxiety often takes its origin from a lack of confidence in situations involving the necessity to handle numerical information. A recent study with adolescents demonstrates that mathematics anxiety can be modeled as a function of both a person's selfregulation skills and self-efficacy beliefs (Jain \& Dowson, 2009). This suggests self-efficacy beliefs with respect to numerical and arithmetic tasks and related self-regulation skills are key factors in the development of anxious reactions to mathematics. Indirectly, such a relationship was confirmed by studies that report positive associations between self-efficacy and performance, independently from the specific task domain (e.g. Bandura \& Locke, 2003; Manstead \& Van-Eekelen, 1998; Newby-Fraser $\&$ Schlebusch, 1998). These findings can be related to Bandura's (1977) theory of self-efficacy that assumes a change of behavior (e.g., math avoidance) in response to (in this case, weak) self-efficacy beliefs. More direct associations have been shown by studies that related test-anxiety to self-efficacy beliefs (e.g., Dykeman, 1994; Hodapp \& Benson, 1997) and even more relevant for the present context, self-efficacy beliefs to mathematics anxiety (Dennis, Daly, \& Provost, 2003).

In summary, personal variables seem to play a critical role in the origin of mathematics anxiety. The description of mathematics anxiety as the outcome of a complex interplay between test anxiety, a generalized fear to fail, negative attitudes towards learning, and low self-efficacy beliefs further supports this point (Bandalos, Yates, \& Thordike-Christ, 1995).

\section{Gender as a Critical Variable}

Research on the relationship between gender, sex and the development of mathematics anxiety is motivated mainly by the finding that females show overall higher levels of mathematics anxiety than males throughout their entire schooling (Devine et al., 2012; Hembree, 1990). Yet, it is difficult to separate social and cultural factors from those of sex per se (Ashcraft \& Ridley, 2005). As a result, the underlying reasons for females' higher mathematics anxiety levels are still unclear. Existing research concerning these differences mainly focuses on the specific impact of mathematics anxiety in females, as compared to their male counterparts.

For instance, although Hembree's meta-analysis (1990) revealed overall higher levels of mathematics anxiety in females, the detrimental effects of anxiety appeared to be stronger on males. That is, mathematical anxious males show more anxiety-related deficits in their mathematics performance, and more avoidance reactions.

A more recent study supports Hembree's (1990) findings of higher anxiety levels in females. However, this study also demonstrates that when test anxiety is controlled, mathematics anxiety is a predictor of mathematical performance only in females (Devine et al., 2012). Without controlling for test anxiety both males and females show negative correlations between mathematics anxiety and mathematical performance. This suggests test anxiety as a potential confound, and emphasizes the relevance of controlling for all kinds of possible confounds.

Another of these potential confounds constitutes a person's willingness to confess to feelings of anxiety, which is generally assumed to be higher in females (Ashcraft \& Ridley, 2005). This is critical for investigations into mathematics anxiety where assessment relies on self-report mostly. Additionally, females tend to be more critical of their own mathematical performance (Flessati \& Jamieson, 1991), and to have lower expectations regarding their mathematical skills, compared to males (e.g. Eccles et al., 1990). However, females' higher anxiety levels may also be related to underlying sex differences in mathematics-associated competencies which, in turn, can be assumed to be related to the development of mathematics anxiety (e.g. spatial processing ability; Maloney et al., 2012). Overall, irespective of both individual mathematical achievement levels and the specific reasons for higher anxiety scores, the available data confirms that females, as compared to males, are generally less confident about their own mathematical abilities, and exhibit higher mathematics anxiety levels (e.g. Hembree, 1990), as well as more stable mathematics anxiety ratings across the years (Ma \& Xu, 2004).

As the case for biologically-determined differences is weak (Ben-Zeev et al., 2005), current research focuses more on the effects of environmental influences, such as gender stereotypes, on mathematics performance and anxiety in females. Regardless of their plausibility, or the lack theory, gender stereotypes seem to critically affect the behavior, and specifically mathematical performance, of female students (Aronson et al., 1999; Beilock et al., 2010). Following Fennema's (1989) autonomous learning behavior model external influences such as stereotypes affect a person's beliefs and attitudes, which in turn affect self-directed learning behavior (e.g. amount of time spent on practice), which ultimately affects individual performance (Ashcraft \& Ridley, 2005). And in this vein, several studies have confirmed differential performance scores after manipulating the "threat of stereotypes" (e.g. Aronson et al., 1999; Spencer, Steele, \& Quinn, 1999). For instance, Spencer and colleagues (1999) found that female students performed worse, when told beforehand that the upcoming test was supposedly harder for females than for males (Ben-Zeev et al., 2005).

\section{Mathematics Anxiety and Performance}

It has been shown repeatedly that there is a significant relationship between levels of mathematics anxiety and performance as assessed by standardized tests. Ashcraft and Ridley (2005) describe this relationship as "not at all surprising" (p. 318). Nevertheless, the question whether mathematics anxiety is the cause or rather consequence of poor performance is not settled.

In general, achievement scores in standardized mathematical performance tests tend to be lower the higher the mathematics anxiety level of an individual is. A negative correlation of - .27 is reported in a meta-analysis on pre-college level studies (Ma, 1999), and, similarly, in a meta-analysis on college-age studies, Hembree (1990) reported a correlation of -.31. Unfortunately, no condensed information is available for elementary school levels. Studies focusing on mathematics anxiety in earlier years 
of schooling do not always find such an effect at all (e.g. Krinzinger et al., 2009; Ramirez et al., in press). That is, anxiety levels and achievement scores do not necessarily show negative correlations at that age. Trying to reconcile such contradictory findings for younger as compared to older students some authors have challenged their own designs (Krinzinger et al., 2009). However, the missing correlation between achievement and mathematics anxiety in younger populations may indicate that mathematics anxiety cannot be fully explained by a failure to perform, and may, thus, not be a consequence of poor mathematical ability. Thomas and Dowker (2000) (as cited in Krinzinger, Kaufmann, \& Willmes, 2009) suggest that the often demonstrated relationship between mathematics anxiety and achievement may actually be age dependent, i.e. getting more pronounced with increasing age and longer schooling. This is in line with the global avoidance theory proposed by Ashcraft and Faust (1994) that describes mathematics anxiety to play a major role in the origin of poor mathematical performance. According to this theory, mathematics anxious individuals tend to avoid mathematics-associated situations and as a result, develop poorer mathematical abilities than their non-anxious peers.

In contrast to these feed forward models, $\mathrm{Wu}$ and colleagues (2012) describe the relationship between mathematical achievement and anxiety as a feedback loop, where anxiety provokes avoidance and negative beliefs about their own competencies, which, in turn, lead to less practice along with resultant difficulties due to lack of practice. The latter leads to even lower self-confidence and, again, to higher anxiety scores.

All in all, the relationship of mathematics anxiety and achievement is more complex than typically acknowledged even by researchers in the field. This is due to mathematics anxiety's twofold influence, i.e. on the one hand, it affects learning motivations and attitudes in general, on the other hand, it specifically interferes with the acquisition of mathematics-related competencies (Ashcraft \& Ridley, 2005).

\section{The Issue of Interpretability of Achievement Scores}

An early study by Ashcraft and Faust (1994) that examined processing speed and accuracy of high versus low mathematically anxious individuals found that anxiety had hardly any effect on a subject's efficiency in simple addition and multiplication tasks. Effects of mathematics anxiety were pronounced only when more complex problems were presented (i.e., twocolumn addition problems). The authors found that while highly anxious individuals tended to respond to test items as quickly as their non-anxious peers, they differed considerably in terms of accuracy. The authors assumed that highly anxious individuals may sacrifice precision in order to complete the task as fast as possible and, thus, escape the aversive situation more quickliy. This speed-accuracy tradeoff (Ashcraft \& Faust, 1994) corroborates the assumption that poor performance of highly anxious individuals may, at least to some extent, be due to avoidance of stressful situations regardless of the individual's true abilities. More recent studies demonstrate that reappraising instructions (e.g., "people who feel anxious during a test might actually do better. [...] arousal could be helping you do well"), may help to change subjects' performance levels to the better (Jamieson, Mendes, Blackstock, \& Schmader, 2010). Finally, when discussing the relationship between anxiety and performance, it is important to consider the possibility that achievement may deteriorate due to more general effects of anxiety related to stressful test situations. Ashcraft and Moore (2009) describe this effect as an affective drop in performance.

\section{The Relationship between Mathematics Anxiety, Performance and Working Memory}

The relationship between working memory functioning, mathematics anxiety and mathematical performance is probably one of the most intensely investigated issues in the field. For example, the deficient inhibition mechanism-theory (Hopko, Ashcraft, Gute, Ruggiero, \& Lewis, 1998) describes mathematics anxious individuals as exhibiting deficient abilities to inhibit attention from shifting towards distracting information. Consequently, working memory resources are withdrawn by taskirrelevant distracters and hence, lacking for processing the task at hand. In mathematics anxious individuals this mechanism seems to be effective also when stimuli are non-mathematical in nature.

Additionally, it has been shown that a mathematics anxious individual's performance does not deteriorate when he or she is confronted with simple arithmetic problems, whereas performance does suffer considerably when the person is confronted with more difficult problems that draw on working memory resources more heavily (Ashcraft \& Kirk, 2001). That is, the performance of mathematics anxious individuals is more severely affected the more complex a given task is. This dynamics is what Ashcraft and Kirk (2001) refer to as a transitory disruption of working memory.

The processing efficiency theory (Eysenck \& Calvo, 1992), a domain-general model of the relationship between anxiety and cognitive performance, describes anxiety-related performance deficits to be more severe when more working memory resources are needed for task completion. The authors assume the intrusive worrisome thoughts to compete with ongoing cognitive operations for the limited processing resources. Although this theory refers to anxiety in general, it is assumed to apply also for mathematics anxiety (Ashcraft \& Kirk, 2001). The authors suggest that "a major contributor to the performance deficits found for high-math-anxiety participants involves working memory" (2001: p. 225).

\section{Assessment of Mathematics Anxiety}

Only a few years after the concept of mathemaphobia was originally brought to the attention of a wider audience (Gough, 1954), a first diagnostic scale to assess numerical anxiety was published (Dreger \& Aiken, 1957). The authors added three mathematical items to the already established Taylor Manifest Anxiety Scale and thereby constructing a new numerical anxiety scale. Unofficially, this constituted the starting point for research on mathematics anxiety and on its assessment.

Only much later, Richardson and Suinn's mathematical anxiety rating scale (MARS, 1972) was published, providing an assessment instrument that was developed exclusively to investigate mathematics anxiety. This original 98-item-questionnaire is based on situational anxiety ratings on a 1 to 5 Likert-type scale, focusing on both everyday situations and more formal settings. Due to its high re-test reliability (.85; Tryon, 1980) and its availability, the MARS became the test of choice for researchers examining mathematics anxiety in college students, regardless of its rather laborious administration (Ashcraft \& Moore, 2009). A more recent reliability generalization analysis conformed its internal consistency and test-retest reliability 
(Capraro, Capraro, \& Henson, 2001).

An alternative instrument to the MARS was offered by Fennema and Sherman (1976) with their mathematics anxiety scale (MAS), one out of several domain-specific Likert-type scales that assesses attitudes assumed to be related to and relevant for mathematics learning and development (other scales surveyed parents' or teachers' attitudes towards math). The MAS is a 12-item scale, intending to assess "feelings of anxiety, dread, nervousness, and associated bodily symptoms related to doing mathematics" (Fennema \& Sherman, 1976: p. 4). For the MAS, a split-half reliability of .89 was reported. Originally designed for high school age, the MAS has been adopted for middle school levels (e.g. Dew, Galassi, \& Galassi, 1984). Despite being published more than 30 years ago, the MAS is still in use (Sherman \& Wither, 2003; Zakaria \& Nordin, 2008).

Only a few years later, Betz (1978) discarded two of the 12 original MAS items, rephrased several others, and thus adapted the scale for assessing mathematics anxiety in college students. A split-half reliability of .92 was reported. However, factor loadings suggest that the main measurement construct of the MAS is worry, a component of anxiety, that has been shown to be provoked mainly by perceptions of insufficient self-efficacy (Bandalos, Yates, \& Thorndike-Christ, 1995).

Later work on alternative assessment tools has relied mainly on the MARS. For instance, in order to investigate mathematics anxiety in children and adolescents, the MARS was adapted by Suinn and Edwards for middle and high school pupils (MARSA; 1982), and for upper elementary school children (MARS-E; Suinn, Taylor, \& Edwards, 1988). For the latter, factor analyticcal evaluation revealed two main situational components of mathematics anxiety, namely mathematics test anxiety and mathematics performance adequacy anxiety. But since the authors did not analyze their data separately by grade or age group, no further insights can be gained about the developmental pathways of these two aspects (Gierl \& Bisanz, 1995). Moreover, these tests are considered to be somewhat dated (Ashcraft \& Moore, 2009).

Considering the complexity of the original MARS, Plake and Parker (1982) provided a 24-item version of the MARS (MARSrevised) to increase assessment efficiency. The revised scale has an estimated alpha coefficient of .98 and correlates with .97 with the full scale, while loading on the same constructs as the original MARS (i.e. state, trait and test anxiety). A principal axes factor analysis of the revised MARS identified two factors, learning mathematics anxiety and mathematics evaluation anxiety (Plake \& Parker, 1982). A recent confirmatory factor analysis however, documented a remarkably poor model-to-data fit for the two-factor structure (Hopko, 2003).

Similarly to Plake and Parker (1982), Alexander and Martray (1989) published another abbreviated version of MARS (AMARS) that amounts to only 25 items, trying to provide a convenient means of assessment available at no cost. For the A-Mars, a factor analysis revealed a three factor structure, individually labeled as math test anxiety, numerical test anxiety and math course anxiety. A two week test-retest analysis revealed a reliability of .86. The correlation with the original MARS is .97 . Although items refer to rather advanced mathematical concepts, A-MARS can also be used at a high school-level.

Since most of the available instruments have been developed for adults or adolescents, and were not appropriate for children in elementary or lower middle school, Chiu and Henry (1990) published a mathematics anxiety scale for children (MASC).
The MASC is yet another adaptation of MARS as it is based on the items of MARS-R (Plake \& Parker, 1982). All items have been revised and two were excluded. Consequently, the MASC consists of 22 revised items and is applicable from fourth to eighth grade. Internal consistency reliability coefficients ranged from .90 to .93 . A principal component analysis revealed a four factor structure with factors labeled mathematics evaluation anxiety, mathematics learning anxiety, mathematics problem solving anxiety, and a fourth and somewhat vague factor mathematics teacher anxiety.

The first instrument that can be used as early as third grade is the mathematics anxiety survey (MAXS) developed by Gierl and Bisanz (1995). The authors adapted questions from MARSE for younger populations, aiming to assess the two aspects of mathematics anxiety that were identified for MARS-E (Suinn et al., 1988). This focus was a consequence of the observation that mathematics anxiety was typically assessed as if it were a unitary construct, even though different aspects of mathematics anxiety were previously identified (e.g. Suinn et al., 1988).

The first scale suitable for studying math anxiety as early as second grade, is the math anxiety questionnaire (MAQ) developed by Thomas \& Dowker (2000) (as cited in Krinzinger, Kaufmann \& Willmes, 2009). Children have to rate experiences of unhappiness and worry caused by problems in arithmetic. The responses are given on a 5 point scale consisting of different pictures that vary for different types of questions. Interestingly, the authors of the German translation of the MAQ reported that this diagnostic tool may actually not be an appropriate means of assessment when the mutual influences of mathematics anxiety and mathematics ability in early years of schooling are under scrutiny (Krinzinger, Kaufmann, \& Willmes, 2009). This emphasizes the need for standardized instruments to assess the development of mathematics anxiety during early primary school years.

More recently, a number of tools suitable for mathematics anxiety assessment of adults and of younger populations were published. However, Hopko and colleagues (2003) reported that the psychometric properties of most currently available abbreviated measures are generally inadequate. The authors point out methodological limitations such as small sample sizes, the lack of test-retest analyses (e.g. Plake \& Parker, 1982), as well as validity data (e.g. Alexander \& Martray, 1989). This being said, Hopko and colleagues developed the abbreviated math anxiety scale (AMAS; 2003) using a large representative sample. The authors assessed internal consistency, test-retest reliability (.85), convergent/divergent validity, as well as the assessment of a model, and generalizability. Additional assessment yielded a 2-factor structure, with the factors learning math anxiety and math evaluation/math test anxiety accounting for $70 \%$ of the overall variance in scores. Due to this high level of psychometric soundness and its convenient 9-item scale, "the AMAS appears to be the test of choice for future work on math anxiety" (Ashcraft \& Ridley, 2005: p. 316) in high school and college level.

Considering the fact that assessment convenience increases with decreasing item quantity, Ashcraft and Moore (2009) tried to correlate only one informal question (i.e., "on a scale from 1 10, how math anxious are you?") with the full A-MARS scores to assess its informative value. Surprisingly, the correlations ranged from .48 to .85 , endorsing this simple assessment tool for preliminary screenings of math anxiety. They emphasized however, that such a one-item assessment tool has to be 
phrased differently for younger students, as they may not be familiar with expressions such as "anxious". Unfortunately, alternative questions that are more suitable for children were not offered.

More recent research into the development of diagnostic measures focuses on the early development of mathematics anxiety which is, as already mentioned, one of the major unresolved issues in the field (Vukovic, Kieffer, Bailey, \& Harari, 2013). For example, Aarnos and Perkkilä (2012) developed a pictorial test for early signs of math anxiety (37 pictures) suitable for six to eight-year-old children. Children are asked to concentrate on pictures (i.e., photographs, drawings or graphical illustrations of mathematical tasks) and have to give spontaneous feedback regarding their affective states and their mathematical intuitions. In order to avoid an entanglement with test anxiety there are no clear-cut correct or incorrect responses for the individual items.

A recently published 8-item scale, the child math anxiety questionaire (CMAQ; Ramirez, Gunderson, Levine, \& Beilock, in press), has also been developed for the use in younger populations. The CMAQ is another adaptation of the MARS-E (Suinn et al., 1988). However, it is reported to be only marginally reliable with a Cronbach's alpha of .55 , which may be related to the fact that alpha values under .70 are not uncommon when investigating attitudes among primary school children.

Another MARS-based diagnostic instrument is the scale for early mathematics anxiety (SEMA; Wu, Barth, Amin, Malcarne, \& Menon, 2012), which was also developed with the aim to create a mathematics anxiety test appropriate and valid for the use in second and third graders. Age-appropriateness was ensured by the items being based on data from content analyses of curricula for grades 2 and 3. The test focuses on the constructs number sense, basic mathematical functions, measure- ment geometry, and mathematical reasoning. However, of SEMA's 20 items only 10 refer to these issues whereas the other 10 focus on feelings of anxiety related to social and testing situations. This structure is mirroring the results of a previous principal component factor analytical study that yielded a two-factor structure, with factors labeled numerical processing anxiety and situational and performance anxiety. For the SEMA, reliability is reported with a Cronbach's alpha coefficient of .87 and a split-half reliability of .77 .

Finally, the most recently published means for mathematics anxiety assessment is another $\mathbf{1 2}$ item scale based on MARS-E and MAQ (Vukovic et al., 2013). Children are asked to indicate the degree to which they consent to different statements mainly related to classroom situations (e.g. I like being called on in math), while choosing their responses from four different options (i.e. yes, kind of, not really, no). Reliability is reported with a Cronbach's alpha of .80. A correlation with MARS-E (in fourth grade) of .48, provides moderate convergent validity (for an overview of all assessment instruments and their applicability see Table 1).

This being said, it has to be pointed out that the general assessment practice which is mainly based on self-reports may be biased. For instance, Ben-Zeev, Duncan and Forbes (2005) state critically that "....verbal reports of anxiety may not be reliable between individuals. Identical responses on a Likert scale may index different levels of subjective anxiety for different people." Furthermore, the authors point out that "correlations between self-reports of anxiety and physiological markers of anxiety tend to be low [...]" (Ben-Zeev et al., 2005: p. 243; see also Ehlers \& Breuer, 1996; Wilhelm \& Roth, 1998). It would, thus, be useful for future research to combine psychophysiological and neuroimaging methods with traditional questionnaire-based assessment approaches to understand mathematics anxiety on a more fine-grained level.

Table 1.

An overview of mathematics anxiety assessment instruments and their applicability for different age groups.

\begin{tabular}{|c|c|c|c|c|c|c|c|c|}
\hline INSTRUMENT & $\begin{array}{c}\text { 1st } \\
\text { grade }\end{array}$ & $\begin{array}{l}\text { 2nd } \\
\text { grade }\end{array}$ & $\begin{array}{l}\text { 3rd } \\
\text { grade }\end{array}$ & $\begin{array}{c}\text { 4th } \\
\text { grade }\end{array}$ & $\begin{array}{l}\text { 5th-6th } \\
\text { grade }\end{array}$ & $\begin{array}{l}\text { Middle } \\
\text { school }\end{array}$ & $\begin{array}{c}\text { High } \\
\text { school }\end{array}$ & College \\
\hline Mathematics anxiety rating scale (MARS; Richardson \& Suinn, 1972) & & & & & & & & \\
\hline Mathematics anxiety scale (MAS; Fennema \& Sherman, 1976) & & & & & & & & \\
\hline MARS-Adolescents (MARS- $A$; Suinn \& Edwards, 1982) & & & & & & & & \\
\hline MARS-Revised (MARS-R; Plake \& Parker, 1982) & & & & & & & & \\
\hline MARS-Elementary (MARS-E; Suinn, Taylor \& Edwards, 1988) & & & & & & & & \\
\hline Shortend MARS (s-Mars; Alexander \& Martray, 1989) & & & & & & & & \\
\hline Mathematics anxiety scale for children (MASC; Chiu \& Henry, 1990) & & & & & & & & \\
\hline Mathematics anxiety survey (MAXS; Gierl \& Bisanz, 1995) & & & & & & & & \\
\hline $\begin{array}{l}\text { Math anxiety questionnaire (MAQ; Thomas \& Dowker, 2000) (as cited in } \\
\text { Krinzinger, Kaufmann \& Willmes, 2009) }\end{array}$ & & & & & & & & \\
\hline $\begin{array}{l}\text { Abbreviated math anxiety scale } \\
\text { (AMAS, Hopko, Mahadevan, Bare, \& Hunt, 2003) }\end{array}$ & & & & & & & & \\
\hline $\begin{array}{l}\text { Scale for early mathematics anxiety } \\
\text { (SEMA, based on MARS; Wu, Barth, Amin, Malcarne, \& Menon, 2012) }\end{array}$ & & & & & & & & \\
\hline Pictorial test for early signs of math anxiety (Aarnos \& Perkkilä, 2012) & & & & & & & & \\
\hline $\begin{array}{l}\text { Child math anxiety questionnaire } \\
\text { (CMAQ, based on MARS-E; Ramirez, Gunderson, Levine, \& Beilock, in press) }\end{array}$ & & & & & & & & \\
\hline 12-item mathematics anxiety scale (Vukovic, Kieffer, Bailey, \& Harari, 2013) & & $\sqrt{2}$ & $\sqrt{2}$ & & & & & \\
\hline
\end{tabular}




\section{Interventions}

Even though poor mathematical competency may be an antecedent to negative experiences in mathematics-related contexts and may increase the risk of mathematics anxiety to develop, it does not suggest itself as a target for intervention. It is rather assumed to be more effective to focus on affective aspects of mathematics-related experiences.

Hembree's (1990) meta-analysis on mathematics anxiety in college and pre-college age revealed that "treatments that resulted in significant mathematics anxiety reduction were accompanied by significant increases in mathematics test scores. The largest increases referred to the treatments providing the largest mathematics anxiety reduction [...]" (p. 43). Poor achievement scores of anxious individuals tend to increase almost to average performance levels after completion of treatments targeting mathematics anxiety as such. And as none of the included intervention studies was based on mathematical instructtion, this data corroborates with the assumption that deficient mathematical performance may be reduced as a consequence of reduced mathematics anxiety.

Furthermore, Hembree (1990) compared classroom interventions and out-of-class psychological treatments in terms of their effects on mathematics anxiety and performance respectively. It was shown that whole-class psychological treatments (i.e. behavioral or cognitive-behavioral approaches trying to relieve "emotionality" toward mathematics and worry about mathematics), as well as whole-class interventions that focused on numerical abilities were neither effective in alleviating mathematics anxiety, nor concerning improvements of mathematical performance. Individual trainings, however, specifically systematic desensitization, anxiety management and conditioned inhibition training, were successful for both, while cognitive modifications (i.e. restructuring of false beliefs and threatening ideas) showed moderate effects.

As a consequence, recent publications (e.g. Maloney \& Beilock, 2012), refer to treatment of affective aspects rather than skills trainings when considering remedial approaches to mathematics anxiety. Appraoches such as writing down worries prior to mathematics tests (Park, Ramirez, \& Beilock, 2011) (as cited in Maloney \& Beilock, 2012), reappraising certain physiological responses related to threat (Jamieson et al., 2010), or stressing the need for regulation strategies for more efficient control of negative emotions (Lyons \& Beilock, 2011) are the first choice when dealing with mathematics anxiety. And finally, since mathematics anxiety causes avoidance of related contexts which, again, does entail detrimental effects on learning success (e.g. Ashcraft \& Faust, 1994; Wu et al., 2012), it is beyond question that interventions have to start as early as possible.

\section{Conclusion}

Summarizing the current state of research on mathematics anxiety, the main message is that more systematic research also integrating neurocognitive methods is needed in order to gain a better understanding of the critical factors that determine the development of mathematics anxiety, of its dynamics over time, and its effect for the individual and its cognitive and emotional development.

On the one hand, there is not enough data on the prevalence and manifestations of mathematics anxiety in younger populations, on how the different variables that were previously iden- tified to be related to mathematics anxiety interact in the course of development, and on the longitudinal effects of mathematics anxiety. On the other hand, intervention studies should be implemented in order to evaluate different remedial approaches and their effectiveness for different age groups.

The only way to gain deeper insights into the underlying mechanisms of the development of mathematics anxiety will be through longitudinal investigations that compare anxious and non-anxious individuals over an adequate period of time, i.e. starting as early as possible, ideally at pre-school age, and ending only after completion of formal schooling. In order to work out possible causal links between the relevant factors identified by previous studies, the collected data should range from information regarding an individual's social and cultural background to the data on his or her domain-general and domain-specific cognitive abilities. Additionally, future research should guard against the collection of potentially biased data (e.g. self-reports). Thus, assessment in the context of research on mathematics anxiety should be made more objective by including (psycho-)physiological (e.g. ECG or EDA) or even neuroimaging methods (e.g. fMRT; Young, Wu, \& Menon, 2012) into the study designs.

In conclusion, future studies on mathematics anxiety that combine multi-method research designs with longitudinal approaches may help to generate more complex models of the dynamics of mathematics anxiety over time, its determining factors, and its detrimental effects for the individual and development.

\section{REFERENCES}

Aarnos, E., \& Perkkilä, P. (2012). Early signs of mathematics anxiety? Procedia-Social and Behavioral Sciences, 46, 1495-1499. doi: $10.1016 /$ j.sbspro.2012.05.328

Alexander, L., \& Martray, C. R. (1989). The development of an abbreviated version of the Mathematics Anxiety Rating Scale. Measurement and Evaluation in Counseling and Development, 22, 143150 .

Aronson, J., Lustina, M. J., Good, C., Keough, K., Steele, C. M., \& Brown, J. (1999). When white men can't do math: Necessary and sufficient factors in stereotype threat. Journal of Experimental Social Psychology, 35, 29-46. doi:10.1006/jesp.1998.1371

Ashcraft, M. H., \& Faust, M. W. (1994). Mathematics anxiety and mental arithmetic performance: An exploratory investigation. Cognition \& Emotion, 8, 97-125. doi:10.1080/02699939408408931

Ashcraft, M. H., \& Kirk, E. P. (2001). The relationships among working memory, math anxiety, and performance. Journal of Experimental Psychology: General, 130, 224-237. doi:10.1037/0096-3445.130.2.224

Ashcraft, M. H., Krause, J. A., \& Hopko, D. R. (2007). Is math anxiety a mathematical learning disability? In D. B. Berch, \& M. M. M. Mazzocco (Eds.), Why is math so hard for some children? (pp. 329-348). Baltimore, MD: Brookes Publishing.

Ashcraft, M. H., \& Moore, A. M. (2009). Mathematics anxiety and the affective drop in performance. Journal of Psychoeducational Assessment, 27, 197-205. doi:10.1177/0734282908330580

Ashcraft, M. H., \& Ridley, K. S. (2005). Math anxiety and its cognitive consequences-A tutorial review. In J. I. D. Campbell (Ed.), Handbook of mathematical cognition (pp. 315-327). New York: Psychology Press.

Bandalos, D. L., Yates, K., \& Thorndike-Christ, T. (1995). Effects of math self-concept, perceived self-efficacy, and attributions for failure and success on test anxiety. Journal of Educational Psychology, 87, 611-623. doi:10.1037/0022-0663.87.4.611

Bandura, A. (1977). Social learning theory. New York: General Learning Press. 
Bandura, A., \& Locke, E. (2003). Negative self-efficacy and goal effects revisited. Journal of Applied Psychology, 88, 87-99. doi:10.1037/0021-9010.88.1.87

Beilock, S. L., Gunderson, E. A., Ramirez, G., \& Levine, S. C. (2010). Female teacher's math anxiety affects girls' math achievement. PNAS, 107, 1860-1863. doi:10.1073/pnas.0910967107

Ben-Zeev, T., Duncan, S., \& Forbes, C. (2005). Stereotypes and math performance. In J. I. D. Campbell (Ed.), Handbook of mathematical cognition (pp. 235-249). New York: Psychology Press.

Betz, N. E. (1978). Prevalence, distribution, and correlates of math anxiety in college students. Journal of Counseling Psychology, 25, 441-448. doi:10.1037/0022-0167.25.5.441

Capraro, M. M., Capraro, R. M., \& Henson, R. K. (2001). Measurement error of scores on the mathematics anxiety rating scale across studies. Educational and Psychological Measurement, 61, 373-386. doi:10.1177/00131640121971266

Chiu, L. H., \& Henry, L. L. (1990). Development and validation of the mathematics anxiety scale for children. Measurement and evaluation in counseling and development, 23, 121-127.

Dennis, K., Daly, C., \& Provost, S. C. (2003). Prevalence, contributing factors, and management strategies for test and maths anxiety in first-year psychology students. Australian Journal of Psychology, Supplement, 55, 176.

Devine, A., Fawcett, K., Szücs, D., \& Dowker, A. (2012). Gender differences in mathematics anxiety and the relation to mathematics performance while controlling for test anxiety. Behavioral and Brain Functions, 8, 1-9. doi:10.1186/1744-9081-8-33

Dew, K. H., Galassi, J. P., \& Galassi, M. D. (1984). Math anxiety: Relation with situational test anxiety, performance, physiological arousal, and math avoidance behavior. Journal of Counseling Psychology, 31, 580-583. doi:10.1037/0022-0167.31.4.580

Dreger, R. M., \& Aiken, L. R. (1957). The identification of number anxiety in a college population. Journal of Educational Psychology, 48, 344-351. doi:10.1037/h0045894

Dykeman, B. F. (1994). The effects of motivational orientation, selfefficacy, and feedback condition on test anxiety. Journal of instructional psychology, 21, 114-120.

Eccles, J. S., Jacobs, J. E., \& Harold, R. D. (1990). Gender role stereotypes, expectancy effects, and parents' socialization of gender differences. Journal of Social Issues, 46, 183-201. doi:10.1111/j.1540-4560.1990.tb01929.x

Ehlers, A., \& Breuer, P. (1996). How good are patients with panic disorder at perceiving their heartbeats? Biological Psychology, 42, 165-182. doi:10.1016/0301-0511(95)05153-8

Eysenck, M. W., \& Calvo, M. G. (1992). Anxiety and performance: The processing efficiency theory. Cognition and Emotion, 6, 409434. doi: $10.1080 / 02699939208409696$

Fennema, E. (1989). The study of affect and mathematics: A proposed generic model for research. In D. B. McLeod, \& V. M. Adams (Eds.), Affect and mathematical problem solving: A new perspective (pp. 205-219). New York: Springer. doi:10.1007/978-1-4612-3614-6_14

Fennema, E., \& Sherman, J. A. (1976). Fennema-Sherman Mathematics Attitudes Scales: Instruments designed to measure attitudes toward the learning of mathematics by females and males. Journal for Research in Mathematics Education, 7, 324-326. doi: $10.2307 / 748467$

Flessati, S. L., \& Jamieson, J. (1991). Gender differences in mathematics anxiety: An artefact of response bias? Anxiety, Stress \& Coping, 3, 303-312.

Gierl, M. J., \& Bisanz, J. (1995). Anxieties and attitudes related to mathematics in grades 3 and 6. The Journal of Experimental Education, 63, 139-158. doi:10.1080/00220973.1995.9943818

Gough, M. F. (1954). Mathemaphobia: Causes and treatments. Clearing House, 28, 290-294.

Harper, N. W., \& Daane, C. J. (1998). Causes and reduction of math anxiety in preservice elementary teachers. Action in Teacher Education, 19, 29-38. doi:10.1080/01626620.1998.10462889

Hembree, R. (1990). The nature, effects and relief of mathematics anxiety. Journal for Research in Mathematics Education, 21, 33-46. doi: $10.2307 / 749455$

Hodapp, V., \& Benson, J. (1997). The multidimensionality of test anxiety: A test of different models. Anxiety, Stress \& Coping, 10, 219-245. doi:10.1080/10615809708249302

Hopko, D. R. (2003). Confirmatory factor analysis of the math anxiety rating scale (revised). Educational and Psychological Measurement, 63, 336-351. doi:10.1177/0013164402251041

Hopko, D. R., Ashcraft, M. H., Gute, J., Ruggiero, K. J., \& Lewis, C. (1998). Mathematics anxiety and working memory: Support for the existence of a deficient inhibition mechanism. Journal of Anxiety Disorders, 12, 343-355. doi:10.1016/S0887-6185(98)00019-X

Hopko, D. R., Mahadevan, R., Bare, R. L., \& Hunt, M. K. (2003). The abbreviated math anxiety scale (AMAS): Construction, validity, and reliability. Assessment, 10, 178-182. doi:10.1177/1073191103010002008

Jackson, C. D., \& Leffingwell, R. J. (1999). The role of instructors in creating math anxiety in students from kindergarten through college. The Mathematics Teacher, 92, 583-586.

Jain, S., \& Dowson, M. (2009). Mathematics anxiety as a function of multidimensional self-regulation and self-efficacy. Contemporary Educational Psychology, 34, 240-249. doi:10.1016/j.cedpsych.2009.05.004

Jamieson, J. P., Mendes, W. B., Blackstock, E., \& Schmader, T. (2010). Turning the knots in your stomach into bows: Reappraising arousal improves performance on the GRE. Journal of Experimental Social Psychology, 46, 208-212. doi:10.1016/j.jesp.2009.08.015

Krinzinger, H., Kaufmann, L., \& Willmes, K. (2009). Math anxiety and math ability in early primary school years. Journal of Psychoeducational Assessment, 27, 206-225. doi: $10.1177 / 0734282908330583$

Lyons, I. M., \& Beilock, S. L. (2011). Mathematics anxiety: Separating the math from the anxiety. Cerebral Cortex, 22, 2102-2110. doi:10.1093/cercor/bhr289

Ma, X. (1999). A meta-analysis of the relationship between anxiety toward mathematics and achievement in mathematics. Journal for Research in Mathematics Education, 30, 520-540. doi: $10.2307 / 749772$

Ma, X., \& Xu, J. (2004). The causal ordering of mathematics anxiety and mathematics achievement: A longitudinal panel analysis. Journal of Adolescence, 27, 165-179. doi:10.1016/j.adolescence.2003.11.003

Maloney, E. A., \& Beilock, S. L. (2012). Math anxiety: Who has it, why it develops, and how to guard against it. Trends in Cognitive Sciences, 16, 404-406. doi:10.1016/j.tics.2012.06.008

Maloney, E. A., Waechter, S., Risko, E. F., \& Fugelsang, J. A. (2012). Reducing the sex difference in math anxiety: The role of spatial processing ability. Learning and Individual Differences, 22, 380-384. doi:10.1016/j.lindif.2012.01.001

Manstead, A. S. R., \& Van-Eekelen, S. A. M. (1998). Distinguishing between perceived behavioral control and self-efficacy in the domain of academic intentions and behaviors. Journal of Applied Social Psychology, 28, 1375-1392. doi:10.1111/j.1559-1816.1998.tb01682.x

Newby-Fraser, E., \& Schlebusch, L. (1998). Social support, self-efficacy and assertiveness as mediators of student stress. Journal of human behavior, 34, 61-69.

Plake, B. S., \& Parker, C. S. (1982). The development and validation of a revised version of the mathematics anxiety rating scale. Educational and Psychological Measurement, 42, 551-557. doi: $10.1177 / 001316448204200218$

Ramirez, G., Gunderson, E. A., Levine, S. C., \& Beilock, S. L. (in press). Math anxiety, working memory and math achievement in early elementary school. Journal of Cognition and Development.

Richardson, F. C., \& Suinn, R. M. (1972). The mathematics anxiety rating scale: Psychometric data. Journal of Counseling Psychology, 19, 551-554. doi:10.1037/h0033456

Rotzer, S., Loenneker, T., Kucian, K., Martin, E., Klaver, P., \& von Aster, M. (2009). Dysfunctional neural network of spatial working memory contributes to developmental dyscalculia. Neuropsychologia, 47, 2859-2865. doi:10.1016/j.neuropsychologia.2009.06.009

Sherman, B., \& Wither, D. (2003). Mathematics anxiety and mathematics achievement. Mathematics Education Research Journal, 15, 138-150. doi:10.1007/BF03217375 
Spencer, S. J., Steele, C. M., \& Quinn, D. M. (1999). Stereotype threat and women's math performance. Journal of Experimental Social Psychology, 35, 4-28. doi:10.1006/jesp.1998.1373

Stuart, V. B. (2000). Math curse or math anxiety? Teaching Children Mathematics, 6, 330-338.

Suinn, R. M., \& Edwards, R. (1982). The measurement of mathematics anxiety: The mathematics anxiety rating scale for adolescentsMARS-A. Journal of Clinical Psychology, 38, 576-580. doi:10.1002/1097-4679(198207)38:3<576::AID-JCLP2270380317> 3.0.CO;2-V

Suinn, R. M., Taylor, S., \& Edwards, R. W. (1988). Suinn mathematics anxiety rating scale for elementary school students (MARS-E): Psychometric and normative data. Educational and Psychological Measurement, 48, 979-986. doi:10.1177/0013164488484013

Tryon, G. S. (1980). The measurement and treatment of test anxiety. Review of Educational Research, 50, 343-372. doi: 10.3102/00346543050002343

Turner, J. C., Midgley, C., Meyer, D. K., Gheen, M., Anderman, E. M., Kang, Y. et al. (2002). The classroom environment and students' reports of avoidance strategies in mathematics: A multimethod study. Journal of Educational Psychology, 94, 88-106. doi: $10.1037 / 0022-0663.94 .1 .88$

Vukovic, R. K., Kieffer, M. J., Bailey, S. P., \& Harari, R. R. (2013). Mathematics anxiety in young children: Concurrent and longitudinal associations with mathematical performance. Contemporary Educational Psychology, 38, 1-10. doi:10.1016/j.cedpsych.2012.09.001

Wilhelm, F. H., \& Roth, W. T. (1998). Taking the laboratory to the skies: Ambulatory assessment of self-report, automatic, and respiratory responses in flying phobia. Psychophysiology, 35, 596-606. doi: $10.1017 /$ S0048577298970196

Wu, S. S., Barth, M., Amin, H., Malcarne, V., \& Menon, V. (2012). Math anxiety in second and third graders and its relation to mathematics achievement. Frontiers in Psychology, 3, 162. doi: $10.3389 /$ fpsyg.2012.00162

Young, C. B., Wu, S. S., \& Menon, V. (2012). The neurodevelopmental basis of math anxiety. Psychological Science, 23, 492-501. doi: $10.1177 / 0956797611429134$

Zakaria, E., \& Nordin, M. N. (2008). The effects of mathematics anxiety on matriculation students as related to motivation and achievement. Eurasia Journal of Mathematics Science and Technology Education, 4, 27-30. 